\title{
FAKTOR-FAKTOR YANG BERHUBUNGAN DENGAN KEIKUTSERTAAN SUAMI DALAM KELUARGA BERENCANA DI WILAYAH PUSKESMAS KECAMATAN PULOGADUNG JAKARTA TIMUR
}

\author{
Willa Follona \\ Poltekkes Kemenkes Jakarta III \\ Email:willafollona@gmail.com
}

\begin{abstract}
The responsibility of men in terms of family planning is very important in the role of family planning programs. However, there is an imbalance in the number of contraceptive participation in female and male FP acceptors. The participation of men is still very low, compared to female. The purpose of this study is to analyze the relationship between husband characteristics seen from the factors of age, education, occupation, ethnicity, religion, income, number of children, also about husband knowledge, attitudes husband and wife I family support, and access to media / participation of husband as KB acceptor. This is a cross sectional study of 90 husbands chosen purposively in Pulogadung Sub District in September 2016. The results showed that there was a significant positive correlation between knowledge with the participation of respondents as Family Planning acceptors, the higher the knowledge level, the higher the participation of husband as the acceptors of family planning with $p$ value 0.022 (OR $=4,818$; 95\% CI 1.476 to 15.728). There was a significant positive correlation between attitudes with the participation of respondents as family planning acceptors, the higher the attitudes they have, the higher the participation of husbands as the acceptors of family planning $p$ value 0,007 (OR =13,813; 95\% CI 2,286 to $66,111)$. Health workers are expected to further promote the promotion of male KB acceptor services, through the provision of family planning education in the form of counseling and family approaches concerning the importance of family planning for men. For those have become acceptors are expected to be role models by spreading to their peer.
\end{abstract}

Keywords: Participation, husband, family planning.

\section{ABSTRAK}

Tanggung jawab pria dalam hal KB sangat penting dalam peran serta program Keluarga Berencana. Namun terjadi ketimpangan jumlah partisipasi kontrasepsi pada akseptor KB wanita dan pria. Partisipasi pria sebagai akseptor KB masih sangat rendah dibandingkan dengan akseptor KB perempuan.Tujuan penelitian untuk menganalisis hubungan antara karakteristik suami yang dilihat dari faktor umur, pendidikan, pekerjaan, suku, agama, pendapatan, jumlah anak, juga mengenai pengetahuan suami, sikap suami, dan dukungan istri/keluarga, serta akses terhadap media/informasi dengan keikutsertaan suami sebagai akseptor KB. Penelitian ini merupakan penelitian crosssectional pada 90 suami yang dipilih secara purposive di Kecamatan Pulogadung pada bulan September 2016.

Hasil penelitian menunjukkan bahwa terdapat hubungan positif yang signifikan antara pengetahuan dengan partisipasi responden sebagai akseptor Keluarga Berencana yaitu semakin tinggi tingkat pengetahuan maka semakin tinggi pula partisipasi suami sebagai akseptor KB dengan $p$ value 0,022 (OR=4,818; CI 95\% 1,476 hingga 15,728). Terdapat 
hubungan positif yang signifikan antara sikap dengan partisipasi responden sebagai akseptor Keluarga Berencana yaitu semakin tinggi sikap yang dimiliki maka semakin tinggi pula partisipasi suami sebagai akseptor KB p value 0,007 (OR =13,813; CI 95\% 2,286 hingga 66,111). Tenaga kesehatan diharapkan lebih meningkatkan promosi pelayanan akseptor KB pria, melalui pemberian pendidikan KB dalam bentuk penyuluhan dan pendekatan keluarga mengenai pentingnya KB untuk pria. Bagi para suami yang telah menjadi akseptor KB diharapkan dapat menjadi panutan dengan melakukan pendekatanpendekatan kepada lingkungannya sehingga suami yang lain pun turut berperan serta menjadi akseptor $K B$.

Kata kunci: Keikutsertaan, suami, keluarga berencana

\section{PENDAHULUAN}

Program keluarga berencana adalah suatu program untuk membantu para pasangan dan perorangan dalam mencapai tujuan reproduksi mereka, mencegah kehamilan yang tidak diinginkan dan mengurangi insidens kehamilan berisiko tinggi, kesakitan dan kematian membuat pelayanan yang bermutu, terjangkau, diterima dan mudah diperoleh bagi semua orang yang membutuhkan, meningkatkan partisipasi dan tanggung jawab pria dalam praktek Keluarga Berencana. Tanggung jawab pria dalam hal $\mathrm{KB}$ sangat penting dalam peran serta program Keluarga Berencana. (BKKBN, 2003). Namun terjadi ketimpangan jumlah partisipasi kontrasepsi pada akseptor KB wanita dan pria. Menurut hasil Survey Demografi Kesehatan Indonesia (SDKI) tahun 2012 menyatakan partisipasi pria sebagai akseptor KB masih sangat rendah, yaitu 3,1\% dibandingkan dengan akseptor $\mathrm{KB}$ perempuan yaitu $42,6 \%$.
Data partisipasi aktif pria dalam penggunaan $\mathrm{KB}$ di negara berkembang selain Indonesia sudah mencapai angka yang cukup, seperti Bangladesh 8\%, Nepal 24\%, Malaysia 16,8\% (SDKI, 2012). Pengembangan program KB yang secara resmi dimulai sejak tahun 1970 telah memberikan dampak terhadap penurunan tingkat fertilitas total (TFR) yang cukup baik, namun partisipasi pria dalam ber-KB masih sangat rendah yaitu sekitar 3,1\% (SDKI, 2012). Hal ini selain disebabkan oleh keterbatasan kontrasepsi pria, juga oleh keterbatasan pengetahuan pria akan hak dan kesehatan reproduksi serta keadilan gender.

Perbedaan gender yang sangat kuat pada masyarakat Indonesia mengenai $\mathrm{KB}$ dirasakan selama ini. Masyarakat telah menempatkan pria pada posisi yang lebih dominan dari istri sehingga kesediaan pria untuk menjadi akseptor KB lebih rendah daripada akseptor KB wanita. Penelitian Budisantoso (2008) menjelaskan bahwa 
masih ada nilai-ilai sosial budaya negatif yang berhubungan dengan partisipasi pria dalam KB seperti faktor malu terhadap lingkungan apabila pria berpartisipasi dalam $\mathrm{KB}$, masih ada yang menganggap nilai anak laki-laki lebih tinggi daripada anak perempuan dan urusan $\mathrm{KB}$ adalah urusan perempuan. $22 \%$ responden bersikap kurang baik dan menganggap seharusnya yang menjadi akseptor KB adalah hanya wanita.

Rendahnya pengetahuan pria tentang metode kontrasepsi dalam keluarga berencana juga tampak dari persepsi pria yang menyatakan pelasanaan vasektomi membahayakan keselamatan (Budisantoso, 2008). Wahyuni (2013) juga mengungkapkan bahwa terdapat hubungan positif yang signifikan antara pengetahuan dan partisipasi pria dalam vasektomi.

Dengan demikian rendahnya partisipasi pria dalam KB yang dilihat dari berbagai aspek yaitu dilihat dari sisi pria itu sendiri maupun persepsi masyaakat yang kurang menguntungkan, oleh sebab itulah upaya partisipasi pria perlu difokuskan pada faktor-faktor tersebut. Hal mendasar dalam pengembangan program partisipasi pria adalah dalam bentuk perubahan kesadaran, sikap dan perilaku pria maupun istrinya tentang $\mathrm{KB}$, sehingga dalam pengembangan tersebut perlu memperhatikan norma/budaya yang dianut oleh mesyarakat dan ajaran agama. Keterlibatan/dukungan keluarga, tokoh msyarakat dan tokoh agama sangat diperlukan dalam mempromosikan kontrasepsi pria. Selain itu juga diperlukan perbaikan serta peningkatan pelayanan dan rujukan KB baik berupa sarana, prasarana, tenaga maupun biayanya.

Berdasarkan studi pendahuluan di Kecamatan Pulogadung Jakarta Timur, terdapat 33544 pasangan usia subur (PUS), yang mengikuti program keluarga berencana adalah 28419 PUS dengan rincian 29,4\% IUD, 33,3\% suntik, pil 21,5\%, implant 7,3\%, MOW 5,2\%, MOP 0,7\%, dan kondom 2,6\%. Dari data tersebut tampak rendahnya partisipasi pria dalam keluarga berencana, khususnya keikutsertaannya dalam menggunakan kontrasepsi.

Berkenaan dengan hal-hal tersebut diatas penulis ingin melakukan penelitian tentang apakah ada hubungan antara karakteristik pria yang dilihat dari faktor umur, pendidikan, pekerjaan, suku, agama, pendapatan, jumlah anak, juga mengenai pengetahuan pria, sikap pria, dan dukungan istri/keluarga, serta akses terhadap media/informasi dengan keikutsertaan pria sebagai akseptor KB. 


\section{METODE}

Penelitian ini merupakan penelitian analitik menggunakan rancangan cross sectional. Populasi penelitian adalah suami dari pasangan usia subur (PUS) di wilayah Kecamatan Pulogadung. Lokasi penelitian dilakukan di Kecamatan Pulogadung Jakarta Timur. Penentuan lokasi dilakukan secara purposive yaitu sengaja ditentukan dengan alasan Kecamatan Pulogadung memiliki gambaran keikutsertaan/partisipasi suami terhadap KB paling banyak dibandingkan dengan kecamatan lain.

Teknik analisis yang digunakan adalah analisis univariat, bivariat dan multivariat Pada penelitian ini analisis univariat dilakukan terhadap variabel karakteristik suami. Sebelum dilakukan perhitungan bivariat, terlebih dahulu dilakukan uji normalitas pada hasil penelitian. Untuk menganalisis hubungan digunakan uji $C h i$ Square, kemaknaan hasil uji ditentukan berdasarkan nilai $\mathrm{p}<0,05$. Analisis yang digunakan untuk melihat faktor yang paling Pengambilan sampel dilakukan dengan puposive sampling dengan jumlah sampel 90 suami. Sumber data yang digunakan adalah data primer yang diambil secara langsung dari para suami menggunakan kuesioner untuk mengetahui faktor-faktor yang berhubungan dengan keikutsertaan suami dalam keluarga berencana. Pengumpulan data dilakukan pada bulan September-Oktober 2016. Sebelum melakukan pengambilan data telah dilakukan uji etik penelitian. Subjek penelitian juga diberikan lembar persetujuan (informed consent) yang diisi secara sukarela setelah subjek mendapatkan informasi tentang maksud dan tujuan penelitian.

\section{HASIL DAN PEMBAHASAN}

Pada hasil penelitian ini didapatkan mayoritas responden tidak mengikuti $\mathrm{KB}$ yaitu sebanyak 83,3\%. Angka ini sekilas menunjukkan bahwa kesadaran suami untuk mengikuti KB masih rendah. 93,3\% responden berumur lebih dari 25 tahun. Mayoritas suami berpendidikan tinggi SMA dan perguruan tinggi yaitu $75,6 \%$. Sebagian besar $92,2 \%$ responden memeluk agama Islam, 7,8\% memeluk agama Kristen. Berdasarkan jumlah anak diketahui bahwa mayoriyas keluarga memiliki jumlah anak 1 sampai 3 yaitu sebanyak $68,3 \%$. Berdasarkan pendapatan diketahui bahwa mayoritas keluarga memiliki penghasilan yang cukup (lebih dari UMR) yaitu sebanyak 51,1\%. Penghasilan keluaga yang semakin besar akan memudahkan memenuhi segala keperluan keluarga, salah satunya adalah kebutuhan kesehatan. Berdasarkan keterpaparan informasi sebagian besar $72,2 \%$ telah terpapar informasi tentang 
keluarga berencana, namun masih ada $27,8 \%$ yang belum terpapar informasi tentang KB memengaruhi keikutsertaan suami sebagai akseptor $\mathrm{KB}$ adalah uji statistik Regresi Logistik.

Tabel 1 Hubungan Antara Karakteristik Responden Dengan Keikutsertaan Menjadi Akseptor Keluarga Berencana

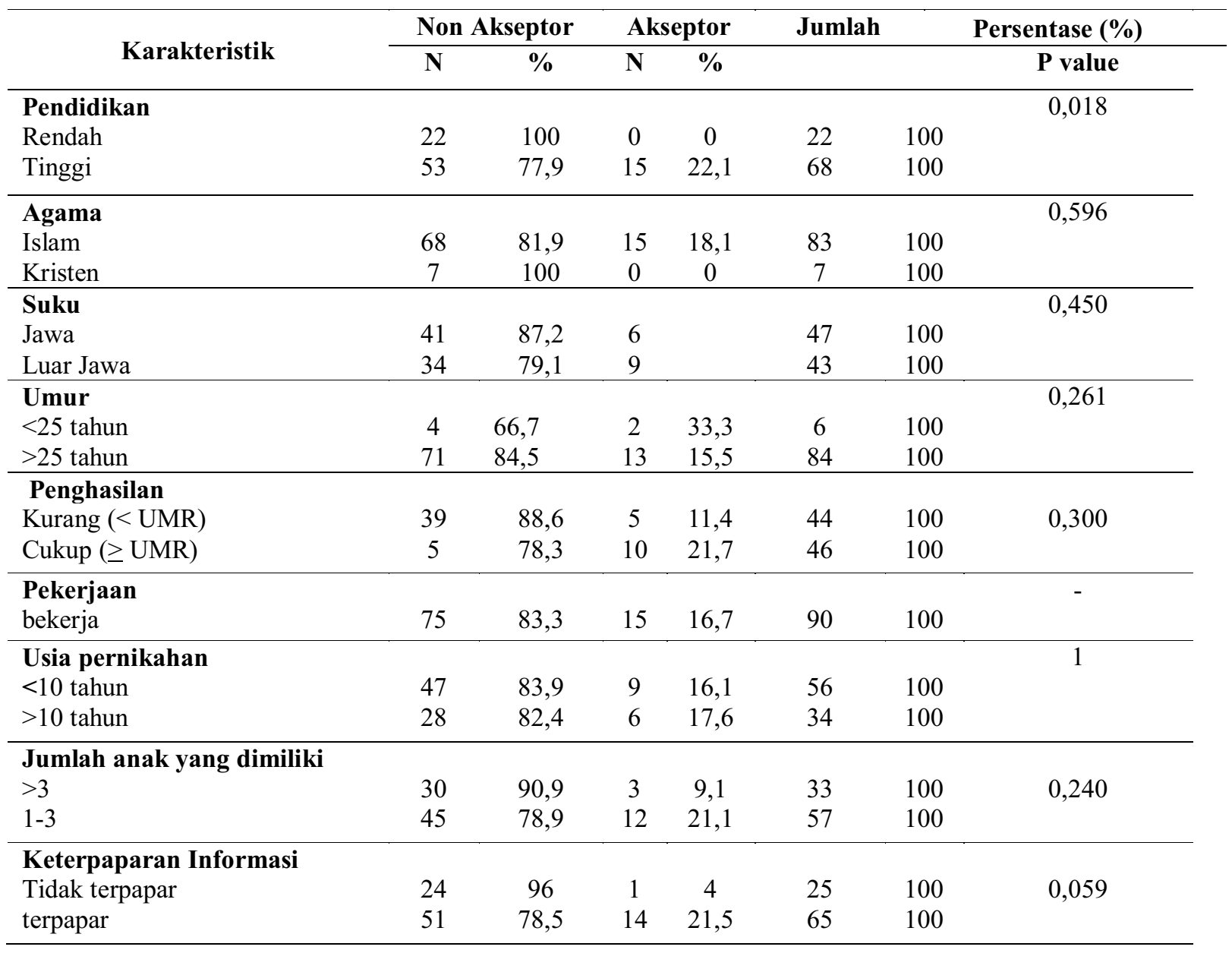

Hubungan antara karakteristik responden dengan keikutsertaan menjadi akseptor keluarga berencana dianalisis dengan metode tabulasi silang. Berdasarkan tabel hasil sebaran pendidikan diketahui bahwa sebagian besar responden yang memiliki pendidikan rendah cenderung untuk tidak menjadi akseptor KB. Hasil uji chi square menunjukkan bahwa karakteristik responden dalam hal pendidikan berhubungan dengan keikutsertaan dalam Keluarga Berencana yang ditunjukkan dengan $p$ value $<0,05$ yaitu 0,018 .

Berdasarkan tabel dapat diketahui bahwa sebagian responden yang lebih terpapar dengan informasi tentang keluarga 
berencana, cenderung untuk menjadi informasi

berhubungan

dengan akseptor KB. Hasil uji chi square keikutsertaan suami dalam KB yang menunjukkan bahwa keterpaparan ditunjukkan dengan $p$ value 0,059

Tabel 2 Hubungan Antara Pengetahuan Responden dengan Partisipasi Sebagai Akseptor KB

\begin{tabular}{lccccccc}
\hline \multirow{2}{*}{ Variabel } & \multicolumn{2}{c}{ Non Akseptor } & \multicolumn{2}{c}{ Akseptor } & \multicolumn{2}{c}{ Total } & \multirow{2}{*}{ Nilai p* } \\
\cline { 2 - 7 } & $\mathbf{N}$ & $\mathbf{\%}$ & $\mathbf{N}$ & $\mathbf{\%}$ & $\mathbf{N}$ & $\mathbf{\%}$ & \\
\hline Rendah & 53 & 91,4 & 5 & 8,6 & 58 & 100 & 0,014 \\
Baik & 22 & 68,8 & 10 & 31,2 & 32 & 100 & \\
\hline
\end{tabular}

Tabel 2 menunjukkan bahwa 31,2\% suami yang ikut serta sebagai akseptor mempunyai pengetahuan yang baik, $91,4 \%$ suami yang tidak ikut serta sebagai akseptor KB mempunyai pengetahuan yang rendah. Terdapat hubungan yang signifikan antara pengetahuan suami dan partisipasi suami sebagai akseptor Keluarga berencana, $p$ value $<0,05$ yaitu 0,014

Tabel 3 Hubungan Antara Sikap Responden Dengan Partisipasi Dalam Keluarga Berencana

\begin{tabular}{lccccccc}
\hline \multirow{2}{*}{ Variabel } & \multicolumn{2}{c}{ Non Akseptor } & \multicolumn{2}{c}{ Akseptor } & \multicolumn{2}{c}{ Total } & \multirow{2}{*}{ Nilai p* } \\
\cline { 2 - 7 } & $\mathbf{N}$ & $\mathbf{\%}$ & $\mathbf{N}$ & $\mathbf{\%}$ & $\mathbf{N}$ & $\mathbf{\%}$ & \\
\hline Negatif & 51 & 96,2 & 2 & 3,8 & 53 & 100 & 0,000 \\
Positif & 24 & 64,9 & 13 & 35,1 & 37 & 100 & \\
\hline
\end{tabular}

Tabel 3 menunjukkan bahwa 35,1\% suami yang ikutserta sebagai akseptor mempunyai sikap yang positif, 96,2\% suami yang tidak ikut serta sebagai akseptor KB mempunyai sikap yang negatif. Terdapat hubungan yang signifikan antara sikap suami dan partisipasi suami sebagai akseptor Keluarga berencana $p$ value 0,000 .

Tabel 4. Hubungan Antara Dukungan Istri Dengan Partisipasi Responden Dalam KB

\begin{tabular}{lccccccc}
\hline \multicolumn{1}{c}{ Variabel } & \multicolumn{2}{c}{ Non Akseptor } & \multicolumn{2}{c}{ Akseptor } & \multicolumn{2}{c}{ Total } & \multirow{2}{*}{ Nilai p* } \\
\cline { 2 - 6 } & $\mathbf{N}$ & $\mathbf{\%}$ & $\mathbf{N}$ & $\mathbf{\%}$ & $\mathbf{N}$ & $\mathbf{\%}$ & \\
\hline Tidak Mendukung & 73 & 85,9 & 12 & 14,1 & 85 & 100 & 0,031 \\
Mendukung & 2 & 40,0 & 3 & 60,0 & 5 & 100 & \\
\hline
\end{tabular}

Tabel 4 menunjukkan bahwa 60,0 \% suami yang ikut serta sebagai akseptor mendapat dukungan dari istri, 85,9\% suami yang tidak ikut serta sebagai akseptor KB tidak mendapatkan dukungan dari istri. Terdapat hubungan 
yang signifikan antara dukungan istri dan

Keluarga berencana $p$ value 0,031 partisipasi suami sebagai akseptor

Tabel 5. Hubungan Antara Dukungan Sosial Budaya Dengan Partisipasi Responden Dalam Keluarga Berencana

\begin{tabular}{lccccccc}
\hline \multirow{2}{*}{ Variabel } & \multicolumn{2}{c}{ Non Akseptor } & \multicolumn{2}{c}{ Akseptor } & \multicolumn{2}{c}{ Total } & \multirow{2}{*}{ Nilai p* } \\
\cline { 2 - 6 } & $\mathbf{N}$ & $\mathbf{\%}$ & $\mathbf{N}$ & $\mathbf{\%}$ & $\mathbf{N}$ & $\mathbf{\%}$ & \\
\hline Tidak mendukung & 47 & 90,4 & 5 & 9,6 & 52 & 100 & 0,047 \\
Mendukung & 28 & 73,7 & 10 & 26,3 & 38 & 100 & \\
\hline
\end{tabular}

Tabel 5 menunjukkan bahwa 26,3 \% suami yang ikut serta sebagai akseptor mendapat dukungan dari sosial budaya 90,4 \%, suami yang tidak ikut serta sebagai akseptor KB tidak mendapat dukungan dari lingkungan/sosial. Terdapat hubungan yang signifikan antara dukungan sosial budaya dan partisipasi suami sebagai akseptor Keluarga berencana dengan $p$ value 0,047

Analisis multivariat digunakan untuk mengetahui pengaruh antara jumlah anak, penghasilan, pengetahuan, sikap, dukungan istri, keterpaparan informasi dan dukungan budaya terhadap partisipasi responden dalam keluarga berencana. Analisis multivariat diawali dengan seleksi bivariat dimana ada 8 variabel independen yang masuk tahap model multivariat karena menghasilkan nilai $\mathrm{p}<$ 0,25 yaitu pendidikan, jumlah anak, pendapatan, pengetahuan, sikap, dukungan istri, dukungan sosial budaya, akses terhadap informasi. Berdasarkan seleksi bivariat, maka didapatkan variabel yang masuk ke pemodelan multivariat adalah variabel jumlah anak ( $p$ value $0,153)$, penghasilan $(0,193)$, pengetahuan $(0,009)$, sikap $(0,001)$, dukungan istri $(0,022)$, dan keterpaparan informasi $(0,076)$.

Tabel 6 Hasil Akhir Analisis Multivariat Antara Variabel Independen Terhadap Partisipasi Suami Sebagai Akseptor Dalam Keluarga Berencana

\begin{tabular}{cccc}
\hline Variabel & OR & $\mathbf{9 5 \%}$ CI & $\boldsymbol{P}$ \\
\hline Pengetahuan & 7.377 & $1,3-40,7$ & 0.022 \\
\hline Sikap & 17.664 & $2,2-144,7$. & 0.007
\end{tabular}


Berdasarkan tabel di atas dapat diketahui bahwa hanya variabel sikap dan pengetahuan yang berhubungan secara signifikan terhadap keikutsertaan suami sebagai akseptor KB, sedangkan variabel jumlah anak, dukungan budaya, dukungan istri, informasi, dan penghasilan sebagai variabel konfounding. Didapatkan bahwa suami yang memiliki pengetahuan baik berpeluang 7,4 kali lebih tinggi untuk ikut serta dalam ber KB dibandingkan suami yang berpengetahuan kurang baik setelah dikontrol dengan variabel sikap, jumlah anak, dukungan budaya, dukungan istri, informasi, penghasilan dengan $p$ value 0,022 dan 95\% CI 1,3-40,7. Didapatkan bahwa suami yang memiliki sikap baik berpeluang 17,7 kali lebih tinggi untuk ikut serta menjadi akseptor KB dibandingkan suami dengan sikap kurang baik setelah dikontrol variabel pengetahuan, jumlah anak, dukungan budaya, dukungan istri, informasi, penghasilan dengan $p$ value 0,007 dan 95\% CI 2,2-144,7.

Karakteristik responden pada penelitian ini $75,6 \%$ pendidikan responden adalah SMA dan perguruan tinggi sehingga diharapkan suami dapat lebih berperan dalam berKB. Berdasarkan tabel hasil sebaran pendidikan diketahui bahwa sebagian besar responden yang memiliki pendidikan rendah cenderung untuk tidak menjadi akseptor KB. Hasil uji chi square menunjukkan bahwa pendidikan berhubungan dengan keikutsertaan suami dalam Keluarga Berencana yang ditunjukkan dengan $p$ value $<0,05$ yaitu 0,018. Hal ini sesuai dengan penelitian Ekawati yang menyatakan pendidikan berpengaruh positif terhadap persepsi pria untuk ber-KB. Pendidikan mempengaruhi proses belajar, makin tingi pendidikan seseorang makin mudah orang tersebut untuk menerima informasi. Dengan pendidikan yang tinggi maka seseorang akan cenderung untuk mendapatkan informasi, sehingga makin banyak pula pengetahuan yang dimiliki. Sebaliknya, pendidikan yang rendah akan menghambat perkembangan sikap seseorang. (Notoatmojo, 2010). Menurut Notoatmojo, pengetahuan merupakan domain yang sangat penting untuk terbentuknya sikap dan perilaku seseorang. Penerimaan sikap dan perilaku yang didasari oleh pengetahuan, kesadaran dan sikap yang positif maka akan menghasilkan perilaku yang akan dapat dipertahankan lebih lama. Setyaningrum dan Melina, 2017, menjelaskan adanya hubungan yang signifikan antara tingkat pendidikan dengan keikutsertaan suami menjadi akseptor $\mathrm{KB}$ dengan $p$ value 0,000 . Hal ini berarti bahwa pengetahuan seseorang dapat dinilai dari tingkat pendidikan 
seseorang, karena makin rendah pendidikan maka cara memperoleh informasi tentang alat kontrasepsi lebih sedikit, baik baik dari orang lain maupun dari media massa, begitu juga sebaliknya (Nototmojo, 2010)

Mayoritas responden memiliki istri yang kurang mendukung suaminya untuk berKB. Hanya 5,6\% istri yang mendukung suami untuk menjadi akseptor $\mathrm{KB}$, sedangkan 94,4\% tidak mendukung suami untuk menjadi akseptor KB. Hasil penelitian menunjukkan $85,9 \%$ suami yang tidak ikut serta sebagai akseptor KB tidak mendapatkan dukungan dari istri. Hasil analisis chi square menunjukkan adanya hubungan yang signifikan antara dukungan istri dengan partisipasi suami sebagai akseptor Keluarga berencana, $p$ value 0,031. Sumiyati dan Hadi,Y, 2017 menyebutkan bahwa rendahnya dukungan pasangan (istri) disebabkan oleh adanya pendapat bahwa kondom dapat mengganggu dan mengurangi kenikmatan, sebab tidak ada persentuhan langsung. Itulah sebabnya, banyak pria yang sebenarnya cocok pakai kondom justru ditentang oleh istri. Menurut Green, 2000, dalam Notoatmojo, 2010, faktor keluarga termasuk istri merupakan salah satu faktor penguat yang membuat seseorang bertindak terhadap obyek tertentu, dalam hal ini dukungan istri merupakan pengaruh yang positif terhadap keputusan suami untuk partisipasi dalam KB. Yeni, dkk (2017) menyatakan pentingnya mendorong para ibu rumah tangga untuk mengajak pasangan ikut serta dalam setiap pengambilan keputusan mengenai penggunaan metode kontrasepsi dengan meningkatkan cakupan partisipasi suami secara langsung dalam menggunakan metode kontrasepsi.

Sebanyak $57,7 \%$ lingkungan sosial budaya mendukung suami untuk menjadi akseptor KB namun 42,2\% tidak mendukung. Hasil penelitian menunjukkan bahwa 26,3 \% suami yang ikut serta sebagai akseptor mendapat dukungan dari sosial budaya, 90,4 \% suami yang tidak ikut serta sebagai akseptor KB tidak mendapat dukungan dari lingkungan/sosial. Terdapat hubungan yang signifikan antara dukungan sosial budaya dan partisipasi suami sebagai akseptor Keluarga berencana dengan $p$ value 0,047. Hasil penelitian ini didukung oleh penelitian Ekarini, 2008, bahwa sosial budaya terhadap $\mathrm{KB}$ berhubungan bermakna dengan partisipasi pria dalam keluarga berencana dengan $p$ value 0,024 .

Mayoritas responden memiliki pengetahuan $\mathrm{KB}$ yang kurang baik yaitu 58 orang atau $64,4 \%$. Berdasarkan hasil uji hipotesis dengan uji regresi logistik, didapatkan bahwa terdapat hubungan 
positif yang signifikan antara tingkat pengetahuan dengan partisipasi sebagai akseptor KB dalam keluarga berencana, dimana $p<0,05 \quad(p=0,022)$. Dimana akseptor KB pria dengan tingkat pengetahuan tinggi memiliki kemungkinan untuk ikut menjadi akseptor KB 4,818 lebih besar daripada akseptor $\mathrm{KB}$ pria dengan tingkat pengetahuan rendah $(\mathrm{OR}=4,818$; $\mathrm{CI}$ 95\% 1,476 hingga 15,728). Hasil penelitian ini didukung oleh penelitian yang dilakukan oleh Wahyuni, dkk (2013) yang menyatakan bahwa terdapat hubungan yang bermakna antara pengetahuan terhadap $\mathrm{KB}$ dengan partisipasi pria dalam penggunaan metode KB Vasektomi. Setyaningrum dan Melina, 2017, juga menyatakan bahwa tingkat pengetahuan berhubungan signifikan dengan keikutsertaan suami menjadi akseptor KB di Desa Sumber Agung Jetis Bantul dengan $p$ value 0,000. Hasil penelitian Fitria, D dan Nuryati, N (2014) menunjukkan bahwa terdapat hubungan antara pengetahuan suami tentang $\mathrm{KB}$ dengan partisipasi suami dalam ber-KB di Kelurahan Kemang dengan $p$ value 0,001 .

Sebagian besar sikap responden tentang suami sebagai akseptor keluarga berencana adalah negatif (58\%) dan $41,1 \%$ adalah positif. Berdasarkan hasil uji hipotesis dengan uji regresi logistik, didapatkan hubungan yang signifikan antara sikap tentang metode kontrasepsi pria dengan partisipasi responden sebagai akseptor KB, dimana $\mathrm{p}<0,005(\mathrm{p}=0,007)$. Akseptor $\mathrm{KB}$ pria dengan sikap tinggi memiliki kemungkinan untuk ikut berpartisipasi sebagai akseptor keluarga berencana (KB) 13,813 kali lebih besar daripada akseptor $\mathrm{KB}$ ria dengan sikap rendah $(\mathrm{OR}=13,813 ; \mathrm{CI} 95 \% 2,286$ hingga 66,111). Hasil penelitian ini sejalan dengan penelitian yang dilakukan oleh Wahyuni, dkk (2013) yang menyatakan bahwa terdapat hubungan yang bermakna antara sikap tentang metode kontrasepsi oleh pria dengan partisipasi pria dalam penggunaan metode KB Vasektomi. Pemahaman yang benar akan pengetahuan tentang penggunaan alat kontrasepsi pria dan sikap terhadap $\mathrm{KB}$ yang lebih positif akan mendukung keterlibatan pria dalam penggunaan alat kotrasepsi

\section{SIMPULAN}

a. Terdapat hubungan yang signifikan antara pengetahuan dengan partisipasi responden sebagai akseptor Keluarga Berencana yaitu semakin tinggi tingkat pengetahuan maka semakin tinggi pula partisipasi suami sebagai akseptor KB.

b. Terdapat hubungan yang signifikan antara sikap dengan partisipasi responden sebagai akseptor Keluarga Berencana yaitu semakin positif sikap 
yang dimiliki maka semakin tinggi

pula partisipasi suami sebagai akseptor

KB.

Saran

Berdasarkan temuan penelitian ini terdapat beberapa hal yang disarankan, seperti berikut:

a. Bagi tenaga kesehatan diharapkan agar lebih meningkatkan promosi pelayanan akseptor KB pria, melalui pemberian pendidikan $\mathrm{KB}$ dalam bentuk penyuluhan dan pendekatan keluarga mengenai pentingnya $\mathrm{KB}$ yang dalam hal ini metode $\mathrm{KB}$ untuk pria.

b. Bagi responden/masyarakat khususnya suami agar lebih menambah wawasan dan pengetahuan mengenai alat kontrasepsi pria yang dapat diperoleh melalui berbagai media massa, media elektronik, tenaga kesehatan, dll

c. Pihak-pihak terkait terutama PLKB dan tenaga kesehatan dapat mengadakan penyuluhan mengenai alat kontrasepsi yang dapat digunakan oleh para suami sehingga dapat meningkatkan pengetahuan tentang keluarga berencana

\section{DAFTAR RUJUKAN}

Budisantoso, SI. 2008. Faktor-faktor Yang berhubungan dengan Partisipasi Pria Dalam Keluarga Berencana Di Kecamatan Jetis
Kabupaten Bantul Tahun 2008. Tesis. Program Pasca Sarjana Universitas Diponegoro Semarang.

Dahlan MS. 2011. Statistik Untuk Kedokteran dan Kesehatan. Jakarta: Penerbit Salemba Medika

Ekarini, SMB. 2008. Analisis Faktorfaktor Yang Berpengaruh Terhadap Partisipasi Pria Dalam Keluarga Berencana di Kecamatan Selo Kabupaten Boyolali. Tesis. Program Pascasarjana Universitas Diponegoro Semarang.

Fitria, D. and Nuryanti, S., 2014. Hubungan Antara Pengetahuan Suami Tentang KB Dengan Partisipasi Suami Dalam Ber-Kb Di Kelurahan Kemang Kabupaten Bogor. Jurnal Ilmiah Kesehatan Diagnosis, 5(5), pp.627-631.

Maharyani HE, Handayani Sri. 2010. Hubungan Karakteristik Pria dengan Keikutsertaan Pria Menjadi Akseptor Keluarga Berencana Di Wilayah Desa Karangduwur Kecamatan Petanahan Kabupaten Kebumen Jawa Tengah. Jurnal Kesmas, Vol. 4, No.1, 71-75

Mahat K, Pacheun $\mathrm{O}$ and Taechaboonsermsak P. 2010. Intention to Accept Vasectomy among Married Men in Kathmandu, Nepal. Asia Journal of Public Health Vol 1 No 1 hal 8-14. Didapatkan dari http//www.asiaph.org/admin/ing.top ic diakses tanggal 15 November 2016

Notoatmodjo S. Ilmu Perilaku Kesehatan. Jakarta: Rineka Cipta; 2010

Notoatmodjo S. Promosi Kesehatan dan Perilaku Kesehatan. Jakarta: Rineka Cipta; 2012 
Satari MH, Wirakusumah FF. Konsistensi Penelitian dalam Bidang Kesehatan. Bandung: Refika Aditama; 2011.

Setyaningrum, N. and Melina, F., 2017. Faktor-faktor Yang Berhubungan Dengan Keikutsertaan Suami Menjadi Akseptor Kb Di Desa Sumber Agung Jetis Bantul. Jurnal Kesehatan Samodra Ilmu, 8(1).

Sumiyati, S. and Hadi, Y., 2017. FaktorFaktor Yang Mempengaruhi

Wahyuni, NPDS, Suryani N, Murdani P. 2013. Hubungan Pengetahuan dan Sikap Akseptor KB Pria Tentang Vasektomi Serta Dukungan Keluarga Dengan Partisipasi Pria dalam Vasektomi (Di Kecamatan Tejakula Kabuaten Buleleng). Jurnal Magister Kedokteran Keluarga Vol. 1, No.1. 80-91
Yeni, Y., Mutahar, R., Etrawati, F. and Utama, F., 2018. Paritas Dan Peran Serta Suami Dalam Pengambilan Keputusan Terhadap Penggunaan Metode Kontrasepsi. Media Kesehatan Masyarakat Indonesia, 13(4), pp.362-368.

Penggunaan Alat Kontrasepsi Kondom. Jurnal Kesehatan Metro Sai Wawai, 6(1), pp.8-15.

Survei Demografi dan Kesehatan Indonesia 2012. Badan Kependudukan dan Keluarga Berencana Nasional. Badan Pusat Statistik. Kementrian Kesehatan. Measure DHS ICF International. http://chnrl.org/pelatihandemografi/SDKI-2012.pdf 